\title{
Macrogeographic patterns in B-chromosome and inversion polymorphisms of the grasshopper Trimerotropis pallidipennis
}

\author{
VA Confalonieri \\ Universidad de Buenos Aires, Facultad de Ciencias Exactas y Naturales, \\ Departamento de Ciencias Biológicas, Intendente Güiraldez y Costanera Norte, \\ (1428) Buenos Aires, Argentina
}

(Received 10 June 1994; accepted 16 February 1995)

\begin{abstract}
Summary - South American populations of Trimerotropis pallidipennis are polymorphic for pericentric inversions and B-chromosomes. Previous studies revealed the existence of altitudinal, latitudinal and longitudinal clines for 9 chromosomal sequences, whose repetition in independent groups of populations and over a wide area suggested the action of natural selection. The frequencies of B-chromosomes were analyzed in 25 samples from Argentina. In some of them, the B-chromosome interfers with the genetic control of chiasma formation, which is partly conditioned by inversions. Multiple regression analyses revealed that the frequency of B-carriers in each population is significantly associated with latitude (negatively) and longitude (positively), and that the frequency of inversions significantly decreases at higher altitudes and latitudes. The pattern of distribution observed for B-carriers is most probably related to the suitability of habitats. These results agree with the parasitic model, which claims that higher incidence of the B-chromosome in natural populations is associated with more favorable environments.
\end{abstract}

Orthoptera / polymorphism / B-chromosome / natural selection / inversion

Résumé - Répartition macrogéographique des polymorphismes du chromosome B et d'inversion chez la sauterelle Trimerotropis pallidipennis. Les populations sudaméricaines de Trimerotropis pallidipennis sont polymorphes pour des inversions péricentriques et les chromosomes $B$. Les études antérieures ont révélé l'existence de clines altitudinaux, latitudinaux et longitudinaux pour neuf séquences chromosomiques, dont les répétitions dans des groupes indépendants de populations et sur une vaste région suggèrent l'action de la sélection naturelle. Les fréquences des chromosomes $B$ ont été analysées dans 25 populations d'Argentine. On peut observer que dans quelques échantillons le chromosome $B$ intervient dans le contrôle génétique de la formation du chiasma, qui est conditionné partiellement par les inversions. Une analyse de régression multiple révèle que la fréquence des porteurs de $B$ dans chaque population est associée significativement à leur situation en latitude (négativement) et longitude (positivement), et que la fréquence des 
inversions diminue significativement en fonction de l'altitude et de la latitude. Le modèle de distribution observé pour les porteurs de $B$ est très probablement en relation avec la qualité des habitats. Les résultats concordent avec le modèle parasitaire selon lequel de hautes fréquences du chromosome $B$ dans les populations naturelles sont associées à des conditions plus favorables de milieu.

orthoptère / polymorphisme / chromosome B / inversion / sélection naturelle

\section{INTRODUCTION}

South American populations of Trimerotropis pallidipennis (Orthoptera) $(2 n=23$ $\checkmark \mathrm{XO})$ are particularly interesting from an evolutionary standpoint because of the occurrence of pericentric inversions and B-chromosome polymorphisms (Mesa, 1971; Vaio et al, 1979; Goñi et al, 1985; Confalonieri, 1988, 1994; Confalonieri and Colombo, 1989) contrasting with North American populations that are structurally monomorphic (Coleman, 1948; White, 1949, 1951). Previous studies revealed the existence of altitudinal, latitudinal and longitudinal clines for 9 chromosomal sequences, whose repetition in independent groups of populations and over a wide area suggested that natural selection maintains these polymorphisms (Confalonieri and Colombo, 1989; Confalonieri, 1994). Minimum temperature and humidity were considered as the possible selective agents. With respect to genetic recombination, inversion polymorphisms are also associated to an important chiasma localization (usually near or at telomeric positions), which leads to an inverse association between total chiasma frequency and the mean number of heteromorphic bivalents per male (H) (Goñi et al, 1985; Confalonieri, 1988). A B-chromosome was observed in almost every population from Argentina and in some of them this chromosome is presumably interfering with the genetic control of chiasma conditions (Confalonieri, 1992).

The present paper reports a macrogeographic pattern of distribution of $\mathrm{B}$-frequencies in relation to those of inversion sequences. These results are discussed in the light of the parasitic and heterotic models of maintenance of B polymorphisms.

\section{MATERIALS AND METHODS}

Twenty-five samples of $T$ pallidipennis collected in several provinces of Argentina were cytologically analyzed (table I); 159 males belonging to some of these samples were previously studied for chiasma conditions (Confalonieri, 1992). Testes were fixed in 1:3 acetic acid/ethanol and squashed in acetic orcein.

In order to weight the regression analysis, B-chromosome frequences were transformed according to the method of Christiansen et al (1976), which takes into account differences in sample size. 
Table I. Samples of Trimerotropis pallidipennis analyzed from Argentina.

\begin{tabular}{|c|c|c|c|c|c|c|c|}
\hline Sample & $\mathrm{N}$ & B & $\mathrm{H}$ & I & $A L T$ & $L A T$ & $L O N G$ \\
\hline Ampimpa* & 18 & 0.11 & 1.61 & 2.9 & 2040 & 26.67 & 66.02 \\
\hline Las Gredas* & 14 & 0.29 & 2.00 & 4.9 & 1924 & 28.82 & 67.48 \\
\hline Famatina* & 13 & 0.31 & 1.85 & 6.4 & 1560 & 28.93 & 67.52 \\
\hline Chilecito* & 20 & 0.36 & 1.64 & 6.3 & 1101 & 29.17 & 67.50 \\
\hline Nonogasta* & 18 & 0.29 & 1.39 & 6.7 & 934 & 29.30 & 67.50 \\
\hline Vichigasta* & 8 & 0.13 & 1.37 & 6.4 & 867 & 29.48 & 67.48 \\
\hline Catinzaco* & 15 & 0.27 & 0.93 & 6.7 & 737 & 29.67 & 67.38 \\
\hline C Monte & 8 & 0.13 & 0.50 & 7.5 & 972 & 30.92 & 64.66 \\
\hline Balde & 11 & 0.18 & 1.45 & 6.9 & 440 & 33.35 & 66.35 \\
\hline Pescadores & 23 & 0.17 & 1.39 & 7.2 & 566 & 33.32 & 66.47 \\
\hline Chosmes & 16 & 0.07 & 1.46 & 7.3 & 554 & 33.42 & 66.80 \\
\hline El Chacay & 7 & 0.29 & 2.29 & 6.6 & 1150 & 33.08 & 69.08 \\
\hline C del Atuel & 19 & 0.37 & 2.32 & 4.9 & 1100 & 34.87 & 68.65 \\
\hline Chocon & 30 & 0.13 & 2.00 & 3.9 & 381 & 36.66 & 68.75 \\
\hline P del Inca & 14 & 0.08 & 0.00 & 0.0 & 2720 & 32.82 & 69.90 \\
\hline Uspallata & 46 & 0.12 & 1.21 & 1.7 & 1831 & 32.60 & 69.33 \\
\hline Cacheuta & 21 & 0.14 & 2.04 & 5.0 & 1237 & 33.17 & 69.17 \\
\hline San Carlos & 16 & 0.22 & 1.78 & 5.6 & 940 & 33.77 & 69.03 \\
\hline Observatorio & 31 & 0.18 & 0.64 & 6.7 & 827 & 32.88 & 68.85 \\
\hline Maipu & 18 & 0.22 & 0.94 & 7.2 & 768 & 33.00 & 68.66 \\
\hline L Blanca** & 10 & 0.20 & 0.00 & 0.0 & 1276 & 30.03 & 70.11 \\
\hline Plottier ${ }^{* *}$ & 11 & 0.09 & 2.27 & 4.3 & 271 & 38.95 & 68.23 \\
\hline Chelforo** & 17 & 0.12 & 2.00 & 4.3 & 174 & 39.08 & 66.53 \\
\hline Ch Choel ${ }^{* *}$ & 19 & 0.11 & 1.16 & 5.2 & 131 & 39.28 & 65.65 \\
\hline La Adela** & 13 & 0.00 & 1.23 & 5.1 & 79 & 39.02 & 64.08 \\
\hline
\end{tabular}

In Uspallata, data correspond to the sample of 1991. $N$ : sample size. $B$ : B-chromosome carrier frequency. $H$ : mean number of heteromorphic bivalents per male. $I$ : mean number of inverted chromosomes per male. ALT: altitude in meters. LAT and LONG: south latitude and west longitude in degrees. ${ }^{*}$ Data from Confalonieri and Colombo (1989). ${ }^{* *}$ Data from Goñi et al (1985).

\section{RESULTS}

\section{Karyotype, B-chromosome and inversion systems}

The basic male karyotype of $T$ pallidipennis consists of $2 n=23$ chromosomes which can be grouped into 3 size classes: large (L1-L3); medium (M4-M8), including the X-chromosome; and short (S9-S11). The X-chromosome is metacentric, the large elements are submetacentric (Vaio et al, 1979) while both medium and short chromosomes are basically acrocentric (Confalonieri, 1988). The B-chromosome has a distal heterochromatic X-like segment and a proximal isopycnotic region, and is a little larger in size than the S9 chromosome (Mesa, 1971; Vaio et al, 1979; Goñi et al, 1985; Confalonieri, 1988). In C-banded cells, it shows 2 interstitial positively stained bands which coincide with part of the heterochromatic region (Sánchez and Confalonieri, 1993). Furthermore, it is mitotically and meiotically stable. The 
frequencies of carriers in each sample are indicated in table I. In Uspallata, stability of B-frequency was demonstrated in 2 consecutive samples collected in 1991 and 1992 and with respect to a sample of 1984. Six pericentric inversions involve 4 of the medium-sized chromosomes, producing multiple karyomorphs in polymorphic populations (Vaio et al, 1979; Goñi et al, 1985; Confalonieri and Colombo, 1989).

\section{Macrogeographic patterns}

In order to assess possible patterns of distribution of B-frequencies, data from 20 samples collected in a wide altitudinal (ALT), latitudinal (LAT) and longitudinal (LONG) range were used in addition to 5 samples from south Argentina reported in Goñi et al (1985). Table I shows the frequencies of B-carriers in each sample, together with the mean number of heteromorphic bivalents $(H)$ and inversions (I) per male per population. Results of multiple regression of these 3 dependent variables on ALT, LONG and LAT are presented in table II. Two distinct patterns of variation were observed for 2 kinds of polymorphisms. The first clear pattern is demonstrated for supernumerary chromosomes so that the frequency of B-carriers in each sample is significantly associated with its latitudinal and longitudinal situation.

Table II. Multiple regression analyses of the dependent variables $B$ (B-frequency, expressed in sample standard error units), $H$ (mean number of heteromorphic bivalents per individual per population) and $I$ (mean number of inversions per individual per population) on the independent variables altitude (ALT), latitude (LAT) and longitude (LONG).

\begin{tabular}{lllll}
\hline Dependent variable & \multicolumn{1}{c}{ ALT } & \multicolumn{1}{c}{$L A T$} & \multicolumn{1}{c}{ LONG } & $\mathrm{R}^{2}$ \\
\hline$B$ & $-0.0002 \mathrm{NS}$ & $-0.19^{*}$ & $0.39^{*}$ & $0.36^{*}$ \\
$H$ & $-0.0005 \mathrm{NS}$ & $-0.05 \mathrm{NS}$ & $0.07 \mathrm{NS}$ & $0.1 \mathrm{NS}$ \\
$I$ & $-0.003^{* * *}$ & $-0.4^{* * *}$ & $0.13 \mathrm{NS}$ & $0.78^{* * *}$ \\
\hline
\end{tabular}

$R^{2}$ : multiple correlation. ${ }^{*} 0.05>p>0.01 ;^{* *} 0.01>p>0.001 ;^{* * *} p<0.001$; $\mathrm{NS}=$ not significant.

Secondly, the frequency of inversions is highly associated with latitude and altitude in such a way that inversions tend to disappear at higher latitudes and altitudes. As previously shown (Confalonieri and Colombo, 1992), both clines indeed reflect a minimum temperature dependence. The level of inversion polymorphism (measured through the parameter $H$ ) did not show a clear macrogeographic pattern of variation because maximal values are attained at intermediate altitudes and latitudes, so the clines observed depend on which groups of populations are scored.

$T$ pallidipennis, which is endemic to North America, is 1 of the few trimerotropines to have successfully extended its distribution to Andean South America (Vaio et al, 1979), being adapted here to a wide altitudinal range. Rain forests and humid grasslands (in eastern localities) are not inhabited by this species and its basic requirement appears to be the prevalence of arid and semi-arid conditions. This species is not present at southern latitudes. In fact, data from Goñi et al (1985) 
(table I) correspond to populations considered by these authors as marginal, because they are situated at the southern border of the species range. Therefore, more eastern longitudes and southern latitudes are most probably marginal environments for $T$ pallidipennis, just where the frequency of B-carriers tends to be lower.

\section{DISCUSSION}

The longstanding debate about B-chromosomes revolves around the issue of whether these widespread polymorphisms are simply a direct result of the accumulation mechanisms or whether they derive from the action of natural selection (Jones, 1985). The view presently favored inclines to the so-called 'parasitic' model which argues that B-chromosomes are selfish elements and drive is the main force generating this kind of polymorphism (Jones, 1991; Shaw and Hewitt, 1991). An extreme case of selfishness has been recently reported by Nur et al (1988).

However, a great variety of mechanisms of drive, phenotypic effects and origins have been described for B-carriers belonging to different species and even to populations of the same species (Jones and Rees, 1982; Jones, 1985, 1991; Bell and Burt, 1990; Shaw and Hewitt, 1991; Bougourd, 1993). It thus seems inappropriate to unequivocally ascribe a universal model of maintenance for all B-chromosome polymorphisms.

The 2 distinct patterns of variation observed for both B-chromosomes and structural rearrangements in $T$ pallidipennis correspond to different processes of evolution.

All inverted sequences tend to increase in frequency towards lower altitudes and latitudes. These clines probably respond to geographically varying selection related to some climatic variables (Confalonieri, 1994). Moreover, some enzymatic loci could be in linkage disequilibrium with supergenes maintained by inversions, which might be the target of selection.

The clines observed for supernumerary chromosomes following geographical variables are better explained by means of the parasitic model: B-carriers are obviously most frequent in those areas where the species thrive and disappear in circumstances where the burden on fitness is too heavy to bear, $i e$ in marginal environments. Similar situations were found in Myrmeleotettix maculatus, where B-carriers are limited to populations in the south and east of Great Britain which are climatically better for grasshoppers (Hewit and Brown, 1970; Hewitt, 1973), and in Crepis capillaris, where higher B-frequencies are also the reflection of the suitability of the habitats (Parker et al, 1991).

Some of the phenotypic effects of B-chromosomes concerned with recombination at meiosis have often been considered to be of adaptive importance (Jones and Rees, 1982). However, this view has recently been reconsidered (Bell and Burt, 1990; Shaw and Hewitt, 1991). Bell and Burt (1990) proposed the theory of 'inducible recombination' by which individuals with 'parasitic' B-carriers might be expected to increase recombination amongst the autosomes so that new genetic variants that are resistant to infection by B-carriers would be more likely to arise. In fact, the presence of B-carriers is usually associated with an increase in chiasma formation (Jones and Rees, 1985; Bell and Burt, 1990). On this theory, successful 'B-parasites' would be expected to reduce the rate of recombination of their hosts. In $T$ pallidipennis a 
significant decrease of mean chiasma frequency of B-carriers was verified for some populations (Confalonieri, 1992). This effect of B-chromosomes could then be of significance to the long-term survival and evolution of local populations, especially those in less favorable environments.

\section{ACKNOWLEDGMENTS}

I wish to express my sincere thanks to JH Hunziker for critical reading of the manuscript. Financial support from the Consejo Nacional de Investigaciones Cientificas y Técnicas and Universidad de Buenos Aires, through grants to JH Hunziker and JC Vilardi.

\section{REFERENCES}

Bell G, Burt A (1990) B-chromosomes: germ-line parasites which induce changes in host recombination. Parasitology 100, S19-S26

Bougourd S M (1993) Phenotypic effects. In: Abstracts of the 1st B-chromosome Conference. Madrid, 21-25 September 1993 (Universidad Autónoma de Madrid, ed), 58-62

Christiansen FB, Frydenberg O, Hjorth JP, Simonsen V (1976) Genetics of Zoarces populations IX. Geographic variation at three phosphoglucomutase loci. Hereditas 83, 245-286

Coleman LC (1948) The cytology of some western species of Trimerotropis (Acrididae). Genetics 33, 519-528

Confalonieri VA (1988) Effects of centric-shift polymorphisms on chiasma conditions in Trimerotropis pallidipennis (Oedipodinae: Acrididae). Genetica 76, 171-179

Confalonieri VA (1992) B-chromosomes of Trimerotropis pallidipennis: new effects on chiasma conditions. Caryologia 45, 145-153

Confalonieri VA (1994) Inversion polymorphisms and natural selection in Trimerotropis pallidipennis (Orthoptera): correlations with geographical variables. Hereditas 121, 7886

Confalonieri VA, Colombo PC (1989) Inversion polymorphisms in Trimerotropis pallidipennis (Orthoptera): clinal variation along an altitudinal gradient. Heredity 62, 107112

Confalonieri VA, Colombo PC (1992) Polimorfismos de inversión y selección natural en Trimerotropis pallidipennis: correlación con variables climáticas. Actas XXIII Congreso Argentino de Genética, Pergamino, Argentina (Sociedad Argentina de Genetica, ed), 20

Goñi B, de Vaio E, Beltrami M et al (1985) Geographic patterns of chromosomal variation in populations of the grasshopper (Trimerotropis pallidipennis) from southern Argentina. Can J Genet Cytol 27, 259-271

Hewitt G M (1973) Evolution and maintenance of B-chromosomes. Chromosomes Today $4,351-369$

Hewitt G M, Brown F M (1970) The B-chromosome system of Myrmeleotettix maculatus. V. A steep cline in East Anglia. Heredity 25, 363-371

Jones RN, Rees H (1982) B-chromosomes. Academic Press, New York, USA

Jones RN (1985) Are B chromosomes 'selfish'? In: The Evolution of Genome Size (T Cavalier-Smith, ed), John Wiley \& Sons, London, UK, 397-425

Jones RN (1991) B-chromosomes drive. Am Nat 137, 430-442

Mesa A (1971) Polimorfismo cromosómico en Trimerotropis pallidipennis (OrthopteraAcridoidae-Oedipodinae). Rev Per Entom 14, 2 
Nur U, Werren J, Eickbush D, Burke D, Eickbush T (1988) A 'selfish' B chromosome that enhances its transmission by eliminating the paternal genome. Science 240, 512-514

Parker J S, Jones G H, Edgar L A, Whitehouse C (1991) The population cytogenetics of Crepis capillaris IV. The distribution of B-chromosomes in British populations. Heredity $66,211-218$

Sanchez V, Confalonieri V (1993) Chromosome banding pattern in Trimerotropis pallidipennis (Orthoptera: Acrididae). Cytobios 73, 105-110

Shaw D, Hewitt G (1991) B-chromosomes, selfish DNA and theoretical models: where next? In: Oxford Surveys in Evolutionary Biology (D Futuyma, J Antonovics, eds), Oxford University Press, Oxford, OK, Vol 7, 197-223

Vaio E de, Goñi B, Rey C (1979) Chromosomes polymorphism in populations of the grasshopper Trimerotropis pallidipennis from southern Argentina. Chromosoma, 71, 371-386

White M (1949) A cytological survey of wild populations of Trimerotropis and Circotettix. I. The chromosomes of twelve species. Genetics 34, 537-563

White M (1951) Cytogenetics of Orthopteroid insects. Adv Genet 4, 267-330 